\title{
A utilização de tecnologias digitais nos primeiros passos na arte da pesquisa: uma experiência de modelagem
}

\author{
Morgana Scheller, IFC - Câmpus Rio do Sul/PUCRS, morganascheller@yahoo.com.br \\ Maria Salett Biembengut, PUCRS, maria.salett@pucrs.br
}

\begin{abstract}
Resumo: Neste artigo apresenta e reflete sobre a prática de iniciação científica desenvolvida a partir da utilização de modelagem e tecnologias digitais na realização de um projeto de pesquisa básica como meio de vincular matemática e realidade e estimular a arte da pesquisa. Os dados empíricos advieram de estudantes do Ensino Médio de uma Escola Agrícola Pública (IFC), durante um ano letivo. Estes dados, coletados por meio da observação dos fazeres destes estudantes e do material produzido por eles, foram analisados em acordo com a Análise do Conteúdo. Os resultados apontaram que o uso das tecnologias digitais potencializa o trabalho de modelagem matemática e, ambas articuladas com discussões vinculadas a realidade dos envolvidos, promove ao estudante: motivação no aprender a no pesquisar; reflexão e sentido a suas ações e a própria matemática.
\end{abstract}

Palavras-chave: Modelagem, tecnologias digitais, projeto, iniciação científica.

Abstract: This paper introduces and reflects on the practice of scientific research developed from the use of modeling and digital technologies in achieving a basic research project as a means to link mathematics and reality and stimulate art research. Empirical data were derived for high school students of a Public Agricultural School (IFC) during the school year. These data, collected through observation of the doings of these students and the material produced by them, were analyzed according to Content Analysis. The results showed that the use of digital technologies enhances the work of mathematical modeling and related discussions with both articulated the reality of those involved, promotes the student: motivation in learning to search in; reflection and meaning to their actions and mathematics itself.

Keywords: Modeling, digital technology, project, scientific initiation.

\section{Introdução}

Nas instituições de Ensino Médio a pesquisa precisa ser prática frequente nos ambientes escolares. Esta pesquisa deve integrar conteúdos das diversas disciplinas do Curso. A matemática, por exemplo, precisa ir além do modo instrumental e integrar-se às demais ciências. Isso implica que no ensino de matemática deve-se priorizar o conhecimento; conhecimento que não seja apenas aquele a ser 'reproduzido' ou 'repetido'. Um estudante, bem mais do que dominar técnicas e estratégias de cálculo, precisa desenvolver a iniciativa e o senso criativo para saber adaptá-lo a diferentes contextos, usando-as adequadamente em momento oportuno (Brasil, 2008). Pois "nós somos, enquanto organismos que se adaptam e que resolvem problemas, motivados a responder ao nosso meio ambiente e alcançar objetivos e finalidades." (George, 1973, p. 29)

Com esse propósito, aliado a presença de tecnologias digitais, a utilização de softwares, computadores, internet, entre outros adquire uma importância natural como recursos que permitem a abordagem de problemas com dados reais e requerem habilidades de seleção e análise de informações. Nesse sentido, é mister propiciar ao estudante oportunidades para o desenvolvimento de habilidades relacionadas à representação, compreensão, comunicação, pesquisa e, também, à contextualização sociocultural, independente da 
disciplina ou do contexto. A escola pode contribuir estimulando o estudante a desenvolver projetos de pesquisa, tanto no espaço da sala de aula como fora dela. Como defende Demo (1996) pode ser uma oportunidade de iniciar os primeiros passos na arte da pesquisa, despertar no estudante a curiosidade, a autonomia na busca de informações e por fim a expressão de ideias.

Dessa maneira, professores e estudantes podem compartilhar tarefas trilhando por caminhos que culminam no desenvolvimento de conceitos científicos. Documentos oficiais referentes à orientação curricular para o ensino na Educação Básica recomendam trabalhos escolares com questões emergentes do contexto dos estudantes e que integrem tecnologias digitais e currículo. Um trabalho com projetos pode ser um exemplo.

\begin{abstract}
Um projeto pode favorecer a criação de estratégias de organização dos conhecimentos escolares, ao integrar os diferentes saberes disciplinares. Ele pode iniciar a partir de um problema bem particular ou de algo mais geral, de uma temática ou de um conjunto de questões inter-relacionadas. Mas, antes de tudo, deve ter como prioridade o estudo de um tema que seja de interesse dos alunos, de forma que se promova a interação social e a reflexão sobre problemas que fazem parte da sua realidade. São situações a serem trabalhadas sob uma visão interdisciplinar, procurando-se relacionar conteúdos escolares com assuntos do quotidiano dos estudantes e enfatizar aspectos da comunidade, da escola, do meio ambiente, da família, da etnia, pluriculturais, etc. (Brasil, 2008, p. 85)
\end{abstract}

Como a modelagem matemática ${ }^{1}$ tem abordagem relacionada com projetos e estes têm recebidos significativas contribuições, nos últimos anos, das tecnologias digitais como meios de suporte, várias práticas de pesquisa nesse sentido já foram realizadas. Destacam-se aa pesquisas de:

- Araújo (2002) que a partir de um estudo numa turma de Cálculo defendeu que em um ambiente de modelagem matemática e uso das tecnologias, a interação entre pessoas e informática proporcionou novas possibilidades de pesquisa.

- Diniz (2007) que pesquisou como os estudantes utilizam as Tecnologias da Informação e Comunicação (TIC) nos projetos de modelagem matemática no Ensino Superior, durante as aulas de matemática aplicada. Os resultados apontaram que os estudantes utilizaram a internet para realizar parte das suas pesquisas, com uma seleção, a priori, de sites oficiais e também utilizaram softwares gráficos para realizar simulações, elaborar conjecturas e compreender mais facilmente o objeto investigado.

- Postal (2011) que a partir dos pressupostos teóricos da Aprendizagem Significativa, modelagem e o uso da tecnologia como recurso pedagógico desenvolveu uma proposta de ensino de matemática para o estudo de função afim, a partir da utilização do software Graphmática. Assim, os estudantes com o uso do aplicativo computacional utilizaram o software para desenhar vários gráficos e analisar o que ocorria quando modificavam os parâmetros da função. O estudo destacou a colaboração e a cooperação entre os estudantes na realização das atividades.

- Santos (2008) apontou que a associação da modelagem com as TIC favorece a compreensão e estimula o desenvolvimento de atividades. Estas contribuem para o desenvolvimento da criatividade no que diz respeito à busca por soluções para problemas que a sociedade atual pode colocar. Também desenvolvido no Ensino Superior, este estudo permitiu verificar o uso que os estudantes fizeram do computador na exploração ou construção de um modelo matemático, bem como observar aspectos que podem contribuir para aprendizagem da Matemática.

informarba e Malheiros (2007) Franchi (2007) Malheiros (2008) con Bo Borba e Villareal (2005) 
cujas pesquisas, também, envolvem modelagem e TIC objetivaram compreender e atividades ou de projetos desenvolvidos em níveis diferentes de ensino. O propósito principal consistia em explorar conteúdos matemáticos, ou seja, aprender matemática e não necessariamente desenvolver habilidades relacionadas à pesquisa.

Baseados nas pesquisas recentes envolvendo Modelagem e tecnologias digitais, e tendo como premissa que os estudantes tornam-se mais interessados em fazer pesquisa em ambiente extraclasse, a questão que orientou a presente pesquisa foi: o que possibilita a utilização de tecnologias digitais e modelagem à arte da pesquisa no Ensino Médio de Escola Agrícola?

Assim, este presente estudo objetiva apresentar e discutir uma prática de Iniciação Científica desenvolvida no Ensino Médio utilizando a modelagem e tecnologias digitais. Para tanto, a seguir, apresenta-se um esboço teórico utilizado para a contextualização do estudo seguido dos aspectos metodológicos que serviram de orientação e fundamentação do mesmo. Finalizando, apresentam-se os dados e os conhecimentos manifestos e latentes do estudo e a discussão realizada.

\section{Amparando a navegação: da modelagem às tecnologias digitais}

A modelagem na Educação vem sendo divulgada e defendida de maneiras diferentes ao longo de mais de 30 anos de história no cenário brasileiro (Biembengut, 2009). Para esta autora a modelagem é entendida como um conjunto de procedimentos necessários para fazer um modelo cujo processo pode ser utilizado em qualquer área do conhecimento. Já para Bassanezi (2006), seja como estratégia de ensino ou método científico, a modelagem é um processo que envolve teoria e prática, levando o investigador a interagir e entender a realidade que está inserida na investigação, e podendo ter como consequência a ação sobre ela visando transformações.

No contexto da Educação, Biembengut (2004) define a modelagem como um método de pesquisa utilizado, em particular, nas Ciências. Os procedimentos da modelagem são essencialmente os mesmos presentes nas etapas da investigação científica; por assim, defende-se como método na Educação. O propósito é incentivar e envolver os estudantes a fazer pesquisa e ao mesmo tempo aprender matemática, podendo ser utilizada em qualquer fase da escolaridade. Os procedimentos da modelagem, Biembengut (2013) ${ }^{2}$ agrupa em três, a saber:

- $1^{\text {a }}$ fase: Percepção e apreensão: nesta fase ocorre o reconhecimento e delimitação do problema; e a familiarização com o assunto a ser modelado, que consistirá posteriormente num referencial teórico.

- 2 $2^{\text {a }}$ fase: Compreensão e explicitação: após realização a interação com o tema, faz-se a formulação do problema, elaboram-se questões e apontam-se hipótese; posteriormente realiza-se a formulação do modelo.

- $3^{a}$ fase: Significação e expressão: é feita a resolução do problema a partir do modelo e interpretação da solução encontrada. Consiste numa avaliação do modelo procurando verificar se o modelo é ou não válido e a expressão do processo e do resultado.

Nesse estudo utilizou-se se dessa concepção, visto que professor e estudante compartilham tarefas no desenvolvimento do exercício da pesquisa e, ainda, fazem uso das tecnologias digitais como recurso.

Assim como a modelagem, as tecnologias digitais, também, encontram-se destacadas nos estudos das últimas décadas na busca do conhecer e interpretar um fenômeno, visto que devido a ela há mais e melhores maneiras de se aprender. Lévy (1993) destaca que a humanidade, ao longo da sua existência, vem produzindo conhecimentos permeados por tecnologias da inteligência (oralidade, escrita e informática) e considera também que a mídia informática cria condições para mudanças qualitativas na educação A qualidade a qual Lévy 
(1993) se refere, é aquela que surge do coletivo, com a formação das redes e da inteligência vista como um processo em que se incluem vários saberes. Para Papert (1985), ao pensar no uso de computadores aliado ao uso de projetos, só percebe que isto agrega qualidade a aprendizagem, se quem executa o projeto, o faz de posse de seus interesses e vontades Papert (1985, p. 2) pondera que “[...] tecnologia não é a solução, é somente um instrumento.” Logo, práticas escolares de modelagem podem tê-la como instrumento e potencializar a pesquisa na educação, como defende Brasil (2008).

Blum e Niss (1991) afirmam as TIC, usadas nos trabalhos de Modelagem, não só facilitam a resolução de problema como são indispensáveis para validação do modelo matemático. Araújo (2002) considera que o contexto de modelagem já tem incorporado a utilização das TIC, seja para a construção, simulação ou avaliação dos modelos. Amplia suas considerações, relatando que a internet possibilita a coleta de informações para a realização da investigação de um determinado fenômeno, sendo uma ferramenta de grande valia. Para Moran e Masetto (2000) a internet facilita a motivação dos estudantes, pela novidade e pelas possibilidades inesgotáveis de pesquisa que oferece. Ela ajuda a desenvolver a intuição, a flexibilidade mental e a adaptação a ritmos diferentes.

Borba e Penteado (2001), no contexto da modelagem, por sua vez consideram que a informática facilita as visualizações de modelos, possibilita a surgimento de conjecturas e podem levar a descobertas. Para eles os computadores reorganizam o pensamento e contribuem para modificar as práticas do ensino tradicional. Esses autores já destacavam que as tecnologias digitais tornaram-se importantes aliadas em investigações abertas como as que são empreendidas em uma abordagem ligada à modelagem.

\section{Os navegadores e as rotas de navegação: do contexto ao método}

O estudo foi realizado no Instituto Federal Catarinense - Câmpus Rio do Sul, instituição pública de Ensino Técnico Integrado durante o desenvolvimento de um projeto em que os estudantes do Ensino Médio iniciavam a arte da pesquisa. Desenvolvido em ambiente extraclasse com dois estudantes da $2^{\mathrm{a}}$ e $3^{\mathrm{a}}$ série do curso de Técnico em Agroecologia, este projeto estava incluído na proposta da instituição de propiciar ao estudante o contato com a pesquisa básica ${ }^{3}$. A instituição defende um ensino no qual o estudante é instigado a envolverse em um ambiente de pesquisa que propicia não só o desenvolvimento de atividade de pesquisa, mas também, de atividades voltadas para a compreensão da realidade sócioeconômica-cultural, buscando soluções para problemas/curiosidades.

Os projetos de pesquisa, geralmente, proporcionam a integração entre disciplinas e, neste caso especial, com destaque para a pecuária, a matemática e a informática. Alguns desses projetos utilizam a modelagem como método de pesquisa para estudar e compreender fenômenos/problemas existentes em outras áreas do conhecimento no dia a dia, sendo as tecnologias digitais um suporte para o desenvolvimento da pesquisa. É o caso desse estudo em que as atividades foram compartilhadas entre estudantes e orientador.

Para este estudo de caso (Yin, 2001; Bogdan; Biklen, 1994), o projeto desenvolvido pelos estudantes e orientado pela primeira autora iniciou por convite desta, porém sem tema pré-determinado. Após vários temas elencados, optou-se por um situado na área de pecuária leiteira, mais precisamente sobre estudos de curvas de lactação de vacas da raça holandesa, tema este relacionado à área de formação dos estudantes. Ao longo do projeto foi determinado um modelo matemático representativo da curva de lactação tendo como parâmetro a produção inicial de leite. Posteriormente, construiram um instrumento com base no modelo obtido, que servira para a previsão e controle da produção de leite de animais da raça holandesa ao longo da lactação, em uma planilha do Excel. Finalizando, foi produzido um vídeo para a divulgação e socialização do estudo, disponível em site com a mesma nomenclatura do projeto. 
No contexto desta instituição de ensino se inseriu a presente pesquisa de natureza qualitativa, que segundo Bogdan e Biklen (1994) é uma tentativa de compreensão detalhada dos significados e características de situações apresentadas pelos investigadores, em lugar da produção de medidas quantitativas de características ou comportamentos. Este tipo de estudo interessa por investigar o problema em seu ambiente natural (fonte direta dos dados) tais como eles se manifestam nas atividades, nos procedimentos e nas interações entre professor e estudante.

Os dados empíricos advieram da observação e materiais produzidos durante o desenvolvimento do projeto intitulado Modelagem matemática no controle da produção de leite de animais da raça holandesa. As observações de natureza não estruturada ocorreram durante aproximadamente um ano (2011-2012) em encontros semanais de 1,5 a 2 horas e foram sendo registradas num diário de bordo. Elas foram realizadas visando descrever e compreender o que estava ocorrendo em determinadas situações. Também utilizou-se cópias dos materiais escritos produzidos pelos estudantes no decorrer da atividade de pesquisa, tais como arquivos do trabalho, relatório final, pôster e também o vídeo elaborado.

Para a análise dos dados foi utilizado os procedimentos da Análise do Conteúdo (Bardin, 1979). Esse procedimento busca explicar e sistematizar o conteúdo das mensagens e o significado desse conteúdo por meio de deduções lógicas e justificadas, tendo como referência sua origem e o contexto das mensagens ou os efeitos dessa mensagem. Este processo de análise foi realizado em três fases: na primeira, ocorreu a leitura dos registros das observações realizadas e dos materiais produzidos pelos estudantes, sendo realizada a elaboração de indicadores para a interpretação dos resultados; na segunda, ocorreu a codificação, classificação e categorização das informações contidas nos registros; e, na terceira, realizou-se a inferência e a interpretação que objetivam tornar os dados mais válidos e significativos subsidiado pela literatura.

\section{O navegar sob a rota da tecnologia digital e modelagem: resultados e discussão}

\subsection{Da percepção e apreensão}

O desenvolvimento do projeto tomou 'corpo' após a realização de dois encontros. A expressão do estudante $C$ revela o desejo: - "Queremos pesquisar algo relacionado à nossa área (Agroecologia), tanto faz se for ligada a agricultura ou pecuária. Gostamos de conhecer melhor o que ainda não está claro para a gente.”

A escolha do tema foi feita pelos estudantes entre as possibilidades citadas. Os momentos seguintes foram de percepção e apreensão de informações relativas ao tema: curvas de lactação - a fim de delimitar uma situação problema para o projeto. Para Biembengut (2013) essa fase é importante, pois, para que se possa compreender uma situação-problema, um fenômeno ou um tema/assunto de interesse, precisa-se perceber o respectivo contexto e apreender o maior número de informação e dados disponíveis, em primeira instância e, assim, reconhecer e se familiarizar com o tema/assunto.

$\mathrm{Na}$ interação com o tema os estudantes exploraram o conhecimento existente na literatura ou com profissionais da área zootécnica. Os diversos materiais obtidos nessa fase consistiram de textos retirados de livros, revistas e páginas da rede mundial, todos com referência ao tema. Somavam-se a isso algumas tabelas organizadas referentes à produção de leite de vacas holandesas relativa aos cinco últimos anos, cujos dados estavam registrados no setor de zootecnia da escola. Esse material foi guardado, em pasta física e, também, os possíveis, em pasta criada no computador dos estudantes. 
Confirmando Borba e Penteado (2001), os estudantes já nesta primeira fase da modelagem utilizaram das tecnologias digitais para a exploração do tema, seja para procura de informações na internet, seja para elaboração de tabelas e gráficos no Excel. Tal escolha se deu de forma espontânea. Novamente o estudante C considerou: - "É possível encontrarmos bem mais na coisa na internet professora do que na biblioteca. Percebemos isso em nossas primeiras buscas. Na biblioteca o que tem e que é pouco aparece bem espalhado e bastante desatualizado. [...] os dados das lactações já vamos organizar no caderno de campo e após no computador para não gastar tanto tempo".

Outro aspecto a destacar na transição da primeira para a segunda fase da modelagem é explicitado por Bassanezi (2002) quando acrescenta que as calculadoras científicas e os softwares, como o Excel, devem ser usados para dispensar os estudantes dos cálculos. Este dado foi levado em consideração intuitivamente pelos estudantes que inicialmente trabalharam com a calculadora, porém a partir do instante que em exploraram ferramentas do Excel sabendo-as usar, a abandonaram. De acordo com Brasil (2008, p. 89) “as planilhas eletrônicas, [...] podem ser utilizadas como recursos tecnológicos úteis à aprendizagem. Elas oferecem um ambiente adequado para experimentar sequências numéricas e explorar determinadas propriedades".

Biembengut (2013) destaca que a fase de percepção e apreensão (reconhecimento e familiarização do tema) não são disjuntas. Na medida em que se percebem alguns dados, os apreende e esta apreensão permite a percepção de outros dados, outras informações e, assim por diante, num processo cíclico, contudo, crescente. Esta fase da modelagem finalizou com um texto compilado e dados organizados na Tabela 1, considerada também com um modelo.

Tabela 1 - Relação Percentual apresentada pelas lactações dos respectivos em vários estágios da produção de leite tomando como parâmetro a produção inicial.

\begin{tabular}{l|l|l|l|l|l}
\hline Animal & $\begin{array}{l}\text { Produção inicial } \\
(\mathrm{Po})-\mathrm{kg}\end{array}$ & $\begin{array}{l}\text { Produção no } \\
\text { pico (Pp)- kg }\end{array}$ & $\begin{array}{l}\text { Produção } \\
\text { final (Pf) }-\mathrm{kg}\end{array}$ & $\begin{array}{l}\text { Relação Percentual } \\
(\mathrm{Pp}) /(\mathrm{Po})\end{array}$ & $\begin{array}{l}\text { Relação Percentual } \\
(\mathrm{Pf}) /(\mathrm{Po})\end{array}$ \\
\hline 109 & 22 & 34,6 & 21,1 & 1,5727 & 0,9591 \\
\hline 240 & 29,5 & 38,8 & 19,6 & 1,3152 & 0,6644 \\
\hline 240 & 20,4 & 29,2 & 17,5 & 1,4313 & 0,8578 \\
\hline 799 & 25,8 & 32,2 & 19,6 & 1,2480 & 0,7597 \\
\hline 792 & 24,9 & 31,4 & 14,6 & 1,2610 & 0,5863 \\
\hline 808 & 24,3 & 29,7 & 10,8 & 1,2222 & 0,4444 \\
\hline
\end{tabular}

Fonte: Ferreira; Panoch; Scheller (2012).

\subsection{Da compreensão e explicitação}

No início da segunda fase - compreensão e explicitação - destaca-se o diálogo entre a orientadora e o estudante $\mathrm{J}$ indagou:

- “A produção de leite aqui na escola será que tem esse comportamento como vimos na literatura consultada?”

- "Que comportamento?” A professora questionou.

- “Assim, oh! (descreveu o comportamento da curva com o indicador, no ar - produção inicial, aumento, pico e produção decrescendo)”.

Os estudantes estavam procurando compreender um problema já buscando uma forma de explicitá-lo. A indagação do estudante demonstrava que eles passam a não aceitar a realidade de qualquer forma, questionando-a. Não consideram como algo pronto e acabado. Desta maneira, se constituía o problema com apontamento de questões respondidas ao longo do projeto, como por exemplo: a relação entre produção inicial de leite, no pico e produção final em uma determinada lactação (conforme Tabela 1). Como estabelecer tais relações e expressar em linguagem matemática? Que modelo seria representativo da curva de lactação 
tendo como parâmetro a produção inicial? A produção inicial é capaz de projetar uma curva antecipada da lactação do animal?

Os estudantes pretendiam elaborar um modelo que permitisse não apenas a resolução da questão em particular, mas que também servisse para efetuar previsões ou permitir uma (re)criação. Eles utilizaram os conhecimentos que possuíam para obter um modelo $\mathrm{O}$ resultado pode traduzir o que, a nível médio, pode ser construído pelos estudantes.

O modelo algébrico obtido, dividido em duas sentenças, conforme sugestão dos estudantes levou em consideração a relação entre o formato das curvas e o comportamento da lactação do animal. Este modelo permite que se defina e projete uma curva de lactação a partir da produção inicial de um animal. A finalidade do modelo foi atendida levando conforme consideram Biembengut (2004) e Bassanezi (2006).

$$
P(x)=\left\{\begin{array}{lr}
\frac{-17 c}{405000} x^{2}+\frac{17 c}{2250} x+c, & \text { se } 0 \leq x<90 \\
\frac{-3 c}{1000} x+\frac{161 c}{100}, & \text { se } 90 \leq x \leq 300
\end{array}\right.
$$

Os modelos são relações funcionais que incorporam as particularidades do fenômeno analisado (Bassanezi, 2006) e no caso do modelo algébrico acima, $\mathrm{P}(\mathrm{x})$ representa a produção de leite em função do tempo "x" (em dias) de lactação e "c", o valor da produção inicial de leite do animal. Estava efetivada esta segunda etapa da modelagem: o compreender os dados e explicitar um modelo. E isto requer do estudante modelador criatividade, imaginação e persistência. Nesta etapa ocorreu bastante o que Lévy (1993) denomina de possibilidades de simulações.

\subsection{Da significação e expressão}

Nesta fase a tecnologia digital protagonizou o espaço da pesquisa. A validação do modelo foi realizada com o auxílio do Excel e se traduz na retomada dos dados empíricos advindos de experimentos e/ou da literatura aplicando-se ao modelo. - "Se esse modelo não revelar uma curva de aspectos parecidos quer dizer que nosso pensamento falhou e teremos de retomar o estudo. Vai que não é esse caminho. Vamos digitar agora aqui no Excel e ver o que é que dá. Tô até com medo" manifestou o estudante C. O resultado foi o modelo gráfico expresso pela Figura 1.

Figura 1 - Modelo gráfico - Projeção da curva de lactação para uma produção inicial de 20 kg de leite

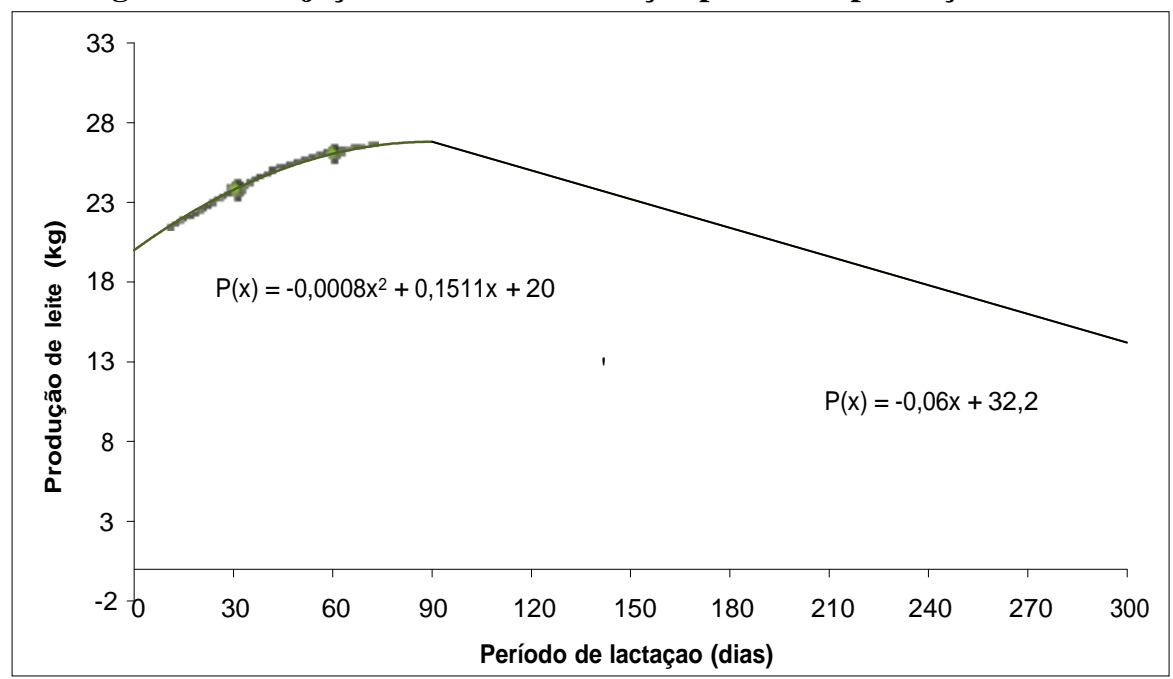

Fonte: Ferreira; Panoch; Scheller (2012). 
Em acordo com Biembengut (2013), a fase da expressão implica em avaliar e verificar a validade do modelo, e por assim, expressá-lo. Neste estudo os estudantes avaliaram o modelo levando em consideração os aspectos da curva de lactação descritos na literatura durante a primeira fase e os valores que o modelo algébrico projetou comparando-os aos dados empíricos.

- "A curva é bastante parecida, vamos ver se os valores ficam muito longe das nossas vacas" comentou a estudante C. - "Acho que deu boa”.

- "Este modelo poderá ajudar os produtores a prever e controlar a lactação de seus animais. Éh massa!” expos o estudante J ao visualizar a curva e preparar-se para a validação do modelo utilizando a planilha do Excel.

É válido salientar que os estudantes destinaram tempo considerável para o estudo de como poderiam trabalhar com a planilha a fim de realizar as ações desejadas. Pode-se considerar que o tópico do projeto mais moroso. Contudo, o navegar pela pesquisa rendeulhes definição de estratégias e conhecimento.

\begin{abstract}
As planilhas eletrônicas são programas de computador que servem para manipular tabelas cujas células podem ser relacionadas por expressões matemáticas. Para operar com uma planilha, em um nível básico, é preciso conhecimento matemático similar àquele necessário ao uso de calculadora, mas com maiores exigências quanto à notação de trabalho [...]. Assim é importante conhecer bem a notação matemática usada para expressar diferentes conceitos, em particular o conceito de função. Além disso, a elaboração de planilhas mais complexas requer raciocínio típico dos problemas que exigem um processo de solução em diferentes etapas (Brasil, 2008, p. 88). Grifo nosso
\end{abstract}

Como etapa final de expressão do modelo, os estudantes elaboraram um instrumento de projeção e controle de curva de lactação em uma planilha do Excel (Figura 2), o qual tem como base o modelo algébrico obtido. Esta parte extrapolou os propósitos iniciais do projeto e demonstra que motivação e interesse impulsionam o estudante a construir formas para resolver seus problemas. "A apropriação de uma resposta a um estímulo ou complexo de estímulos deve depender da motivação (George, 1973, p. 28)”.

Figura 2 - Visão do instrumento elaborado pelas estudantes na planilha Microsoft Excel

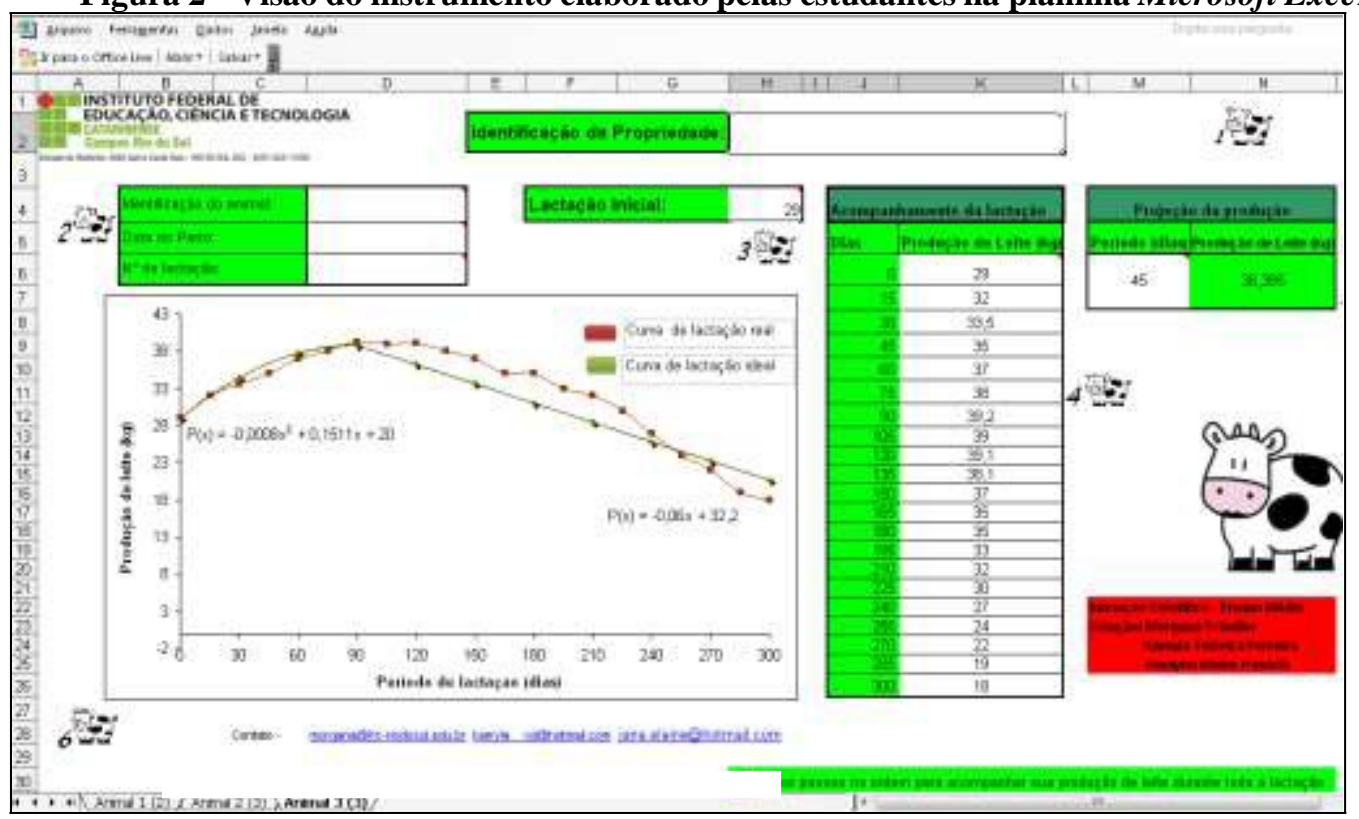

Fonte: Ferreira; Panoch; Scheller (2012). 
O trabalho findou-se com a elaboração do relatório, do pôster utilizado nas socializações de fundamental importância, realizadas em mostras e feiras e ainda, com a elaboração de um vídeo objetivando a divulgação do trabalho, este disponível na internet. Dessa forma, modelagem e tecnologias digitais integraram-se em um só objetivo e culminaram na construção de conhecimento com base em um método de pesquisa: a modelagem. Isto foi possibilitado "porque é dada ao estudante a oportunidade de estudar situações-problema por meio de pesquisa, desenvolvendo seu interesse e aguçando seu senso crítico” (Biembengut, 2004, p. 23).

\section{Finalizando a navegação na rota da tecnologia digital e modelagem}

Todo o navegar até este momento permite a realização de algumas considerações pertinentes à apresentação e à discussão da prática de iniciação científica: objetivo deste estudo. Uma delas é compreender que a modelagem é um método de pesquisa eficaz que permite ao estudante extrapolar os seus conceitos espontâneos e apropriar-se de conceitos mais elaborados, científicos. Conceitos estes, tanto em termos de domínio matemático e tecnológico, quanto conceitos de etapas de pesquisa; instigando a reflexão, as questões e as ações dos estudantes. Outra consideração importante foi que a utilização da tecnologia como instrumento de apoio, especialmente as páginas de consultas on-line e do software Excel, possibilitaram aos estudantes realizarem inferências sobre: o tema da pesquisa, o modelo em suas representações tabular, algébrica e gráfica e, também, a significação e a expressão do modelo. As tecnologias digitais, ora na "posição de protagonista", ora de "coadjuvante", potencializaram as atividades desenvolvidas no projeto. Sem elas, o resultado não seria o mesmo; uma vez que propiciou aos estudantes atingirem um potencial no 'caminhar' pela pesquisa e, consequentemente, na reflexão sobre o alcance de suas descobertas, em particular, sobre a relação da matemática com a realidade.

A tecnologia digital e a modelagem proporcionaram aos estudantes nos caminhos da pesquisa uma postura social ao estudarem um tema não só pelo estudar e sim por considerar indispensável o extrapolar das fronteiras escolares com a socialização e divulgação do instrumento aos produtores de leite e comunidade escolar. Desta forma, contribuiu para a formação da sua cidadania, ao despertar novos olhares, quer sobre a situação investigada, quer sobre a realidade política e social que os envolvia no ambiente que para eles era motivador.

A apresentação e reflexão da prática de iniciação científica finda aqui destacando a afirmação de Papert (1985), que educar consiste em criar situações para que os aprendizes se engajem em atividades que alimente o processo construtivo para pensar e aprender. Processo este em que sujeitos ativos na construção de conhecimento, sujeitos autores, deixem-se levar pelo entusiasmo da pesquisa sob o navegar da tecnologia digital e modelagem.

1 - O termo é utilizado no decorrer do artigo apenas como modelagem.

2 - BIEMBENGUT, M. S. Modelagem no Ensino Fundamental. 2013. (no prelo pela Editora da FURB)

3 - Entende-se na instituição que pesquisa básica ocorre quando o estudante é provocado a desenvolver uma atitude de questionamento, numa perspectiva dialógica, problematizadora e reconstrutiva do conhecimento. E que possibilita uma compreensão das relações entre ciência, tecnologia e sociedade, levando o estudante ter posturas ativas e interessadas em transformações.

\section{Referências bibliográficas}

ARAÚJO, J. L. Cálculo, Tecnologias e Modelagem Matemática: as discussões dos alunos. Rio Claro: UNESP, 2002. Tese de Doutorado. 
BARDIN, L. Análise de conteúdo. Lisboa: Edições 70, 1979.

BASSANEZZI, R. C. Ensino-aprendizagem com modelagem matemática. 3. ed. São Paulo: Contexto, 2006.

BIEMBENGUT, M. S. 30 Anos de Modelagem Matemática na Educação Brasileira: das propostas primeiras às propostas atuais. Alexandria. Florianópolis, 2 (2), 7-32. 2009.

BIEMBENGUT, M. S. Modelagem matemática \& Implicações no Ensino e na Aprendizagem de Matemática. 2. ed. Blumenau: Edifurb, 2004.

BLUM, W.; NISS, M. Applied Mathematical Problem Solving, Modelling, Applications, and Links to Other Subjects - State, Trends and Issues in Mathematics Instruction. Educational Studies in Mathematics, Dordrecht, v. 22, n. 1, p. 37-68, feb. 1991.

BOGDAN, R. C.; BIKLEN, S. K. Investigação qualitativa em Educação: uma introdução à teoria e aos métodos. Lisboa: Porto Editora, 1994.

BORBA, M. C.; MALHEIROS, A. P. S. Internet e Modelagem: desenvolvimento de projetos e o CMV. In: Barbosa, J.; CALDEIRA, A.; ARAÚJO, J. L. Modelagem Matemática na Educação Matemática: pesquisas educacionais. Recife: Sbem, 2007. p. 195-211. v.3.

BORBA, M. C.; VILLARREAL, M. E. Humans-with-Media and Reorganization of Mathematical Thinking: Information and Communication Technologies, Modeling, Visualization and Experimentation. New York: Springer Science+Business Media, Inc., 2005.

BORBA, M. C.; PENTEADO, M. G. Informática e Educação Matemática. Belo horizonte: Autêntica, 2001.

BRASIL. Orientações curriculares para o ensino médio: ciências da natureza, matemática e suas tecnologias. Brasília: MEC, Secretaria de Educação Básica, 2008, v.2.

DEMO, P. Educar pela pesquisa. Campinas: Autores Associados, 1996.

DINIZ, L. N. O Papel das Tecnologias da Informação e Comunicação nos Projetos de Modelagem Matemática. Rio Claro: UNESP, 2007. Dissertação de Mestrado.

FERREIRA, K. T.; PANOCH, J. E.; SCHELLER, M. Modelagem Matemática no controle da produção de leite de animais da raça holandesa. Relatório de Iniciação Científica. Rio do Sul, Instituto Federal Catarinense Câmpus Rio do Sul, 2012.

FRANCHI, R. H. O. L. Ambientes de aprendizagem fundamentados na modelagem matemática e na informática como possibilidades para a Educação matemática. In: Barbosa, J.; CALDEIRA, A.; ARAÚJO, J. L. Modelagem Matemática na Educação Matemática: pesquisas educacionais. Recife: Sbem, 2007. p. 177-194. v.3.

GEORGE, F. Modelos de Pensamentos. Trad. Mário Guerreiro. Petrópolis: Vozes, 1973. LÉVY, P. As tecnologias da Inteligência: O futuro do pensamento na era da informática. Rio de janeiro: Editora 34, 1993. Trad. Carlos Irineu da Costa.

MALHEIROS, A. P. S. Educação Matemática on-line: a elaboração de projetos de modelagem matemática. Rio Claro: UNESP, 2008. Tese de Doutorado.

MORAN, J. M.; MASETTO, M. T.; BEHRENS, M. A. Novas tecnologias e mediação pedagógica. 12. ed. Campinas: Papirus, 2000.

PAPERT, S. Logo: computadores e Educação. São Paulo: Editora Brasiliense, 1985.

POSTAL, R. F.; HAETINGER, C.; DULLIUS, M. M.; SCHOSSLER, D. C. Atividades de Modelagem Matemática visando-se a uma aprendizagem significativa de funções afins, 
fazendo uso do computador como ferramenta de ensino. Alexandria, v.4, n.1, p.153-173, maio 2011.

SANTOS, F. V. Modelagem Matemática e tecnologias de informação e comunicação: o uso que os alunos fazem do computador em atividades de modelagem. Londrina: UEL, 2008. Dissertação de Mestrado.

YIN, R. K. Estudo de caso: planejamento e métodos. Tradução Daniel Grassi. 2. ed. Porto Alegre: Bookmann, 2001. 